\title{
Evaluating Learning Outcomes of Sports Skills through Observation
}

\author{
Ishak Aziz ${ }^{1}$ \\ ${ }^{1}$ Faculty of Sports Sciences, Universitas Negeri Padang, Indonesia \\ Correspondence: Ishak Aziz, Faculty of Sports Sciences, Universitas Negeri Padang, Jl. Prof. Dr. Hamka - Air \\ Tawar, Padang, Sumatera Barat, Indonesia. E-mail: sayutisahara@yahoo.com
}

Received: February 12, 2014 Accepted: February 20, 2014 Online Published: February 28, 2014

doi:10.5539/ass.v10n5p130

URL: http://dx.doi.org/10.5539/ass.v10n5p130

\begin{abstract}
This article focuses on how learning outcomes of sports skills can be evaluated through field observation. The problem arises when the researcher noticed that the ability of physical education teachers in evaluating skills observation is low. There are some factors that influence this ability. The factors are: they cannot differ between cyclic and non-cyclic movement, they are not able to differentiate technical knowledge that is based on quantity or result, and they have less knowledge to apply evaluation through observation. The purpose of this article is to give solution and alternative to physical education teacher in order to conduct a measurement. There are three aspects involved in evaluating a movement. They are: observing, analyzing, and applying. Furthermore, there are three processes involved in learning psychomotor skills, namely, basic learning stage, concentration, and specialization. An individual's ability to perform a movement task can be differentiated by age difference, purpose and motivation, movement experience, ability, coordination, and training frequency. This article focuses on the ability and coordination of the performer. Some special characteristics of movements such as movement structure, rhythm, connectivity, width, speed, and accuracy of movements will also be discussed.
\end{abstract}

Keywords: movement, observation, evaluation

\section{Introduction}

Practical learning is obtained by student through product (result) and process. Product refers to maximal capability of student to perform a practical test by noting how far, how high, how fast a task can be completed. Meanwhile, learning process is looking at the procedure of movement in any given sports. In another word, evaluating skills through observation is done by seeing someone, media, or tools and categorizing it into four aspects such as: cognitive, psychomotor, emotional reaction and interaction (Romiszowski, 1981). Then individuals' behavior obtained through the learning process are categorized into (1) new behavior formed as actual or potential capability, (2) new ability can be performed over a relatively long period, (3) new ability ist obtained through effort. Learning outcomes is an internal capacity which include: (1) intellectual ability refers to the ability that make an individual competent on a particular subject, thus, he/she is able to classify, identify, demonstrate, and generalize movements, (2) cognitive strategy, refers to the ability to use his/her intellectual ability to solve new problem, (3) verbal information refers to the ability to use verbal or non-verbal language to explain a problem, (4) motor ability refers to the ability to consciously coordinate muscular movement, (5) Attitude refers to the preference to accept and refuse intervention (Gagne \& Leslie, 1979). In conducting practical learning process, physical activity or psychomotor movement is necessary. In order to make learning successful and achieve its purpose, strategy and planning is necessary. Surakhmad (1979) says that planning starts from pre-preparation of learning, and the learning process contains (a) the learning material, (b) a purpose, (c) active learning time, (d) active teaching time, (e) specific method to achieve the purpose, (f) teaching aids that supports interaction in situational condition such as: video, handy cam, or other supporting equipment.

Psychomotor domain refers to physical activity such as sports, drama, driving and typing. Harrow, as cited by Salvin (1994), states that the elements in the psychomotor domain are: (1) reflective movement, (2) fundamental movement, (3) perceptual capability, (4) physical ability such as: lift weight, long distance cycling, (5) trained movement, and (6) non-communicable movements. Learning -outcomes of motor movement are a result of increased in ability to perform a skill due to training conditions or obtained from experience, not from the maturation process or temporary motivation and physiology fluctuations. Evaluation of skills through observation can be a tedious job for physical education teachers. This is because it is difficult to observe a movement technique due to the minimum quantity of media, minimal resources, and incapability of teacher to 
accomplish it. Due to the complexity of evaluating learning outcomes in physical education, it necessary to conduct some comprehensive analysis about the characteristic of movement in specific sports. Therefore, this article will further explain the levels that exist in a particular movement and determine the indicators to observe in a coordinated movement.

\section{Discussion}

\subsection{Process of Movement}

In order to do movement task, an individual should begin with the process of observation, then analyze and apply it. Meinel in Kiram (1992) says that there are three categories in the process of learning movement, they are: basic, advanced, and specialization. By going through the levels in the cognitive and affective domain, it can be concluded that a person is capable of doing the movement. For example to solve mathematical problem, cognitive domain is dominant and if student interact with each other, affective domain is more dominant. This can also be apply in physical education, however the psychomotor domain is more dominant. These domains cannot be separated from one another, because when psychomotor domain is active, affective and cognitive domains are supportive. Gultom (2013) also states that to learn a skill, the first thing to do is observe, then ask questions, trying it out, associating it to other movement, explaining it and creating the movement. The principles of evaluation includes a. objectivity, meaning evaluation is based on standards and is not influence by subjectivity of the teacher/evaluator, b. integrated meaning the evaluation is well planned, synonymous with learning activities and is continuous, c. economic, meaning evaluation process is efficient in terms of planning, executing and reporting, $d$. transparent, meaning the evaluation procedures, criterias and results is accessible to all, e. accountable, meaning the evaluator is the responsible for all involve in the evaluation process, and, $\mathrm{f}$. educative, meaning evaluation also serves to motivate and educate students and teachers alike (Gultom, 2013).

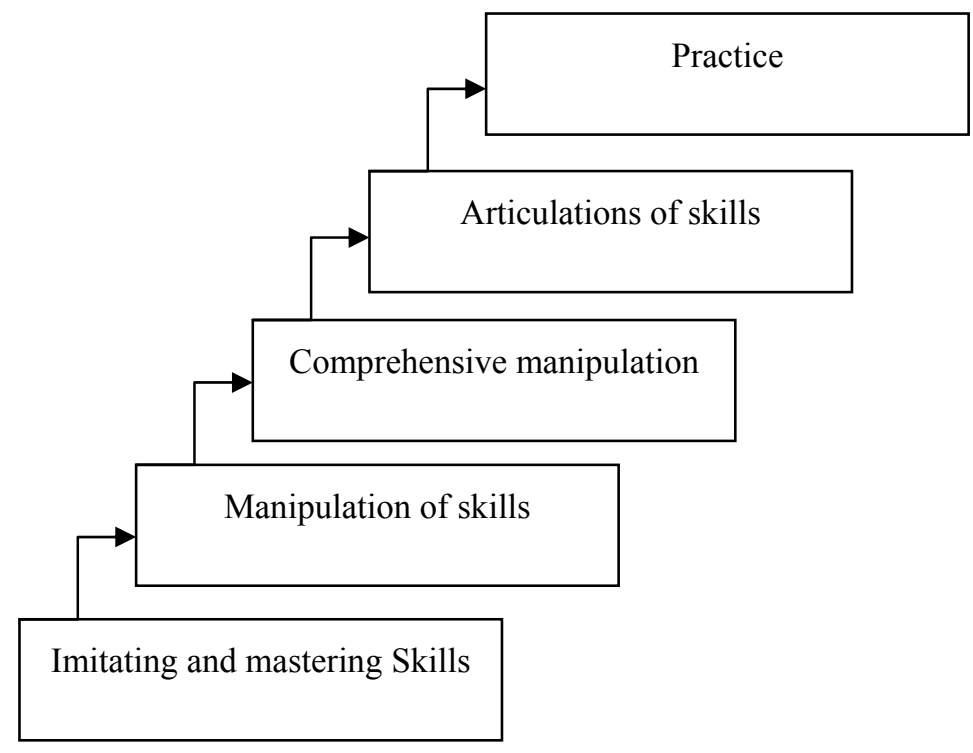

Figure 1. Process of learning a skill

Source: Soekartiwi, Monitoring dan Evaluasi Proyek Pendidikan, 1995

Meanwhile, Soekartiwi (1995) states that the process in learning skills starts from imitating process (see Figure 1). Every individual who would like to do a movement, always start by seeing and looking at examples of the movement. Then, he/she tries to manipulate the movement, which at this stage the movement may be in a rough form. By doing the movement continuously, the next stage of movement is manipulation of movement with greater accuracy, and in the final stage, it will be done thoroughly and articulately. Each process of movement need some time to practice. Without practice, it may be impossible for someone to achieve the final level or mastered the movement well. In evaluating the quality of movement through observation is based on how the process is done or by using the evaluation process. All components of a coordinated movement such as: 1) movement structure, 2) rhythm, 3) fluency, 4) relationship, 5) accuracy, 6) tempo, and, 7) range of movement is look at. Based on this coordinated movement components, the indicators for the evaluation process can be determined. To evaluate the quality of movement, it should be based on the capability of the individual which is appropriate with the individual's coordination level. This means that to evaluate a movement; a teacher cannot 
generalise one group of study. For example in a class, a teacher cannot take for granted that the ability of students is similar. It is necessary to make separation in the student's mastery in movement. Meinel in Fauzan (1998) categorizes individual's capability of movement to three categories, namely:

1) Phase 1 - development and mastery of rough coordination.

2) Phase 2 - development and mastery of smooth movement

3) Phase 3 - mastery, stabilize and automated movement and transfer of movement to various situation.

In order to evaluate quality movement ability also known as evaluation process in psychomotor domain, it has a close relation with observation. In order to use observation in movement evaluation, help from at least two teachers with similar specialization in the subject is necessary. This is based on the needs that must be fulfilled. Based on a survey on school age children, those who likes to do physical activity in rural area is very rare. They incline to use motorcycle rather than walking or doing physical activity. This is appearing so on daily life, there are many motorcycles parked on the school yard, which is supposedly be used for different purposes. The meaning of the statement above is, it is not wrong to evaluate psychomotor domain through product evaluation rather than process. Both of this evaluation can be used, however, observation on the differences on physical condition and fitness of school age children, it is better to evaluate the process rather than the product.. Furthermore, looking at the 2013 curriculum, in order to achieve the purpose of the learning process through evaluation, the process of achieving the objectives should not be neglected. This means attitude plays a role in behavioral changes, thus it is important to include affective and cognitive aspects in the evaluation process. The difference with the previous curriculum is knowledge (cognitive) is the most important aspect while attitude (affective) domain is least important.
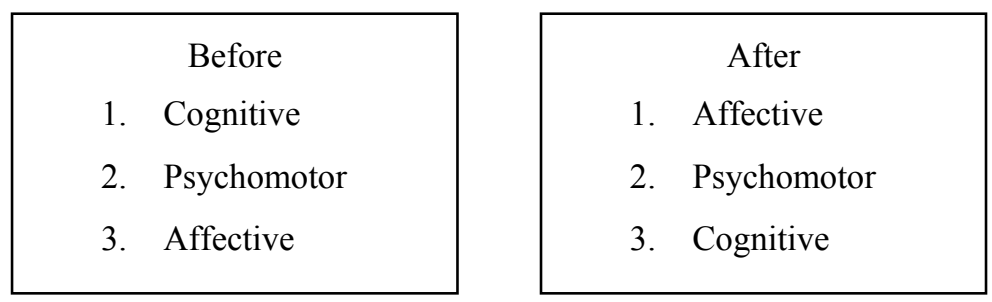

Figure 2. Difference in importance of the domains between previous and current curriculum

Based on the above arguments, it clear that the evaluation of quality is necessary to acknowledge that every individual performing a sports skills possess a variety of abilities. This variation can be based on differences such as age, purpose and motivation, movement experience, ability, coordination, and training frequency. (Kiram, 1992). By acknowledging this differences it will appear that there exist differences in learning level. Therefore, in order to evaluate ability of movement, it is better to take into account the differences stated above. For example, a teacher would like to evaluate the ability of passing, in a volleyball game; meanwhile the level of students' ability to do the skill is varied, therefore, it is better to test the skill in accordance with student's level of ability. Teachers should work together to do the evaluation process. For example: a teacher evaluates basic ability of the above skill, the first step the teacher should establish the indicator of coordination that is necessary, such as: 1) placement of hands when contacting the ball, 2) position of legs when the student bend the knee, 3) contact the ball at the wrist, 4) the height of ball after contacting. By setting the indicator, the next step is to establish the coordination element that should be evaluated on every individual.

\subsection{Determining Coordination Indicator}

The next step is to determine the coordination indicator that is used as an instrument to evaluate the students ability to perform amovement technique. As has been stated earlier, coordination is instrumental towards an individual's mastery of a movement skill. If the movement is well coordinated, teacher can assure that the student master that component of movement. They can be categorized as level three learning phase, meaning skill is stabilize, automated and coordinated and is transferable to various situation and conditions. This can be seen when a subject learns how to do a front roll, indicators such as position of body, feet and hand while squatting in the ready position, position of hands and head when rolling, the form of the body when rolling, direction of roll and and the final position when completing the movement. By mastering these indicators, it can be said that the student understands and is able to perform the front roll very well.

There is specific characteristic in skills learning as stated by Meinel and Reider cited by Fauzan (1999). They say 
that skills learning are mastering, smoothness of movement, stabilizing, and applying motor ability. This is also supported by Rieder stating that skill learning is an escalation of motor coordination process by optimizing external and internal factors with the purposed of mastery of skills. Based on these statements, it can be concluded that there are some main uncertainties in skills learning. They are: skills learning is a process experienced by individual to gain some specific ability. There are three components that determine acquisition of skill which is emotional, cognitive and skills competence. In order to know better the technical aspects in evaluating movement ability, teachers should be knowledgeable on the specific characteristics of movement. The next section will explain how to use the characteristics of coordination in general movement, with an example of the evaluation form.

\subsubsection{Structure of Movement}

Individual who just begins to learn some sports activity in general is not able to demonstrate the basic structure of movement. It is important that when watching movement activity he/she needs to watch it from beginning till the end. This activity is necessary to know the basic movement structure. There are three phases in basic structure of movement; the early phase, main phase, and the late phase. The early phase is the preparation phase that functions to prepare all requirements for the main phase, for example the run when preparing to do a long jump with one foot is on the take-off board. Main phase is the process of application of the movement task at hand, and is this case, taking off with the dominant foot until the body is flying in the air. Meanwhile in the late phase is to control body so that balance is maintained until movement is completed.

\subsubsection{Rhythm of Movement}

In this stage, students have not perfectly mastered the rhythm of movement. Rhythm of movement is one of the characteristics that show the accuracy between space and time. For example, an individual who is beginning to learn the process of kicking, he/she will stop the ball before kicking it. Another example is the lay-up activity in basketball game. Beginners will usually stops after the third steps, take aim and shoots the ball. However, the indicators in basketball lay-up include the range of step, levitation time, body position while in the air, and releasing the ball from the hand. By stating that indicator it will be easier to observe how far students mastered their lay-up techniques.

\subsubsection{Correlation of Movement}

The correlation of movement is how body parts transfer the impulse to another body part at exactly the right time and condition. This means that individuals has the ability to optimally control their movement according to plan. Generally, in order to do overall movement the coordination of some body parts to another is not in ideal condition when someone is in the first phase of learning process. In other word, the transfer of movement that happened is not optimal. The question, how to observe that part of the body? To answer this question, the procedure is to state the indicators. For example, in high jump, the indicators are: the distance between starting point and jumping line, the starting movement that is needed either by using the left or right foot, the placement of feet to jump, the swing time, body position over the bar, and body position when landing. Based on these indicators, the teacher is able to observe the characteristics in the process of correlation of movement.

\subsubsection{Range of Movement}

This characteristic is in the second learning phase whereby coordination is already well established. In this phase, coordination is easy to observe. The range of movement is how much space is taken by overall body parts in order to complete a movement. Individuals in the first learning phase, will usually take-off either before or after the take-off board in long jump. As a result, there is no power efficiency in the movement. To improve the skill, indicators will need to be determined. The indicators includes determining steps taken for the run-up, landing on the take-off board, position of leading leg during flight, position trailing leg with leading leg, preparing for landing, and landing with both legs. By using these indicators, it can help the teacher to observe the range of movement in a long jump.

\subsubsection{Smoothness of Movement}

The meaning of smoothness of movement is the flow of movement, in other word continuity of the movement. For individual in the first learning phase, the movements are jerky. For example, in dribbling a basketball, the indicators are: ball contacts singularly with the palm and eyes do not focus on the ball or hand at all times.

\subsubsection{Speed of Movement}

The speed of movement is a characteristic that is important in sports. Speed is involved in almost all sports movement. The better a person could master a movement, the faster he/she is able to do the movement. However 
in a class, students have varying levels of ability and at various phases of learning, therefore, teacher need to observe carefully in order to make a good decision on the ability of each and every student in the class.

\subsubsection{Accuracy of Movement}

Accuracy of movement means every movement can be done accurately. For example, when a student tries a free shot to the ring in basketball, even without any disturbance from other player, he/she may not be able to score. In contrast, a highly accurate player can repeatedly score from a free shot throw.

\subsection{Observation Technique for Movement Ability}

In order to observe and score movement in practical test, students need to demonstrate some specific movement of skill. The instrument used is a check list with a complete evaluation rubric. Before explaining the score scale, it important to acknowledge that qualitative observation is conducted based on individual characteristic that synchronized with their level of coordination (rough, smooth, automatic). This means teacher may not observe every characteristic of coordination but synchronized it by level of ability that necessary in every coordination level. Observation indicators should be prepared by physical education teachers since they have the kinesthetic experience to do so. For example a teacher needs to observe the coordination in smoothness of movement. The format that can be use is:

Table 1.

Observed aspects
Phase

Note: Ideal; 81 - 100, simple mistakes: 70 - 80, light mistakes: 55-69, big mistakes $<55$ (Fauzan 1995).

1) Evaluation Key. Skill observation can be done in two ways:

i. Evaluation on perfectness of movement/attitude/how movement is performed, and

ii. Evaluation on the product movement (based on accuracy of movement)

2) Checklist for performance

Do muscle power training! The elements that will be evaluated are the perfection in the process and accuracy of movement

Table 2.

\begin{tabular}{|c|c|c|c|c|c|}
\hline Skills evaluated & & & & Score & Note \\
\hline Process & & & Product & & \\
\hline Early phase (score3) & Main Phase (score4) & Ending Phase (score3) & Muscular power test & & \\
\hline
\end{tabular}

Next, do endurance training! The elements that will be evaluated are the perfection in the process and accuracy of movement

Table 3.

\begin{tabular}{|c|c|c|c|c|c|}
\hline Skills evaluated & & & & Score & Note \\
\hline Process & & & Product & & \\
\hline Early phase (score3) & Main Phase (score4) & Ending Phase (score3) & (2.4 km run test) & & \\
\hline
\end{tabular}


Now, do fitness test consisting of: 1)50 Meter sprint, 2) 30 seconds back lift for male and 60 seconds for female 3) sit ups 60 seconds, 4) Sargeant jump, 5) 800 meter run for female and 1000 meter for male. The elements that will be evaluated are the perfection in the process and accuracy of movement

Table 4.

\begin{tabular}{|c|c|c|c|c|c|}
\hline Skills evaluated & & & & Score & Note \\
\hline Process & & & Product & & \\
\hline Early phase (score3) & Main Phase (score4) & Ending Phase (score3) & Fitness test battery & & \\
\hline
\end{tabular}

\section{Conclusion}

Evaluating skills in sports through observation is based on the ability to master a movement learned through varying levels of learning process. Observing the quality of movement in sports is necessary because:

1) Physical education curriculum that combines quality of movement with ability to perform the movement

2) The differences in children's development

3) Individual chances develop at their own rate

\section{References}

Gagne, R. M., \& Briggs, L. J. (1979). Principles of Instructional Design. New York: Holt, Rinehart.

Hos, F. (1999). Teori Gerak. Padang FPOK.

Kiram, Y. (1992). Belajar Motorik. Jakarta. Proyek Peningkatan Tenaga Kependidikan Direktorat Jenderal Pendidikan Tinggi Depertemen Pendidikan dan Kebudayaan.

Muhajir dan Budi Sutrisno. (2013). Buku Guru, Pendidikan Jasmani, Olahraga dan Kesehatan. Untuk SMP/MTsN Kelas VII Kementerian Pendidikan dan Kebudayaan Dilindungi Undang-Undang.

Rahantoknam, B. E. (1986). Belajar Motorik. Jakarta: Proyek Peningkatan Pengembangan Perguruan Tinggi IKIP.

Romiszowski, A. J. (1981). Designing Instructional System: Decision Making in Course Planning and Curiculum Design. New York: Nicholas Publishing Company.

Slavin, R. A. (1994). Educational Psycology. New York: Allyn \& Bacon.

Soekartiwi. (1995). Monitoring dan Evaluasi Proyek Pendidikan.

Winarno, S. (1979). Metode Pengajaran. Bandung: Jemmers.

Winston. Gultom, S. (2013). Paparan Sosialisasi/implementasi Kurikulum 2013 tgl 13 s/d 15 Agustus di Auditorium Kamaluddin Fekon UNP.

\section{Copyrights}

Copyright for this article is retained by the author(s), with first publication rights granted to the journal.

This is an open-access article distributed under the terms and conditions of the Creative Commons Attribution license (http://creativecommons.org/licenses/by/3.0/). 